\title{
REDUÇÃO DE DANOS NO \\ TRATAMENTO DE ALCOOL E OUTRAS DROGAS: uma prática possível para a família? \\ DOI: 10.22289/2446-922X.V4N2A3
}

\author{
Moniele Borges da Silva ${ }^{1}$ \\ Juliana Amorim Pacheco de Oliveira
}

\section{RESUMO}

O presente trabalho apresenta uma revisão bibliográfica conceitual que tem por objetivo entender qual a percepção da família em relação à estratégia de Redução de Danos voltada para o tratamento dos usuários do CAPS-ad, pois é perceptível que atualmente vive-se uma situação crítica em relação ao uso abusivo do álcool e outras drogas. Diante desta realidade, percebeuse a necessidade da implantação de um serviço de saúde substitutivo à internação, que respondesse à demanda destes usuários. Assim, com a necessidade de atendimentos diários, foram criados os Centros de Atenção Psicossociais Álcool e Drogas (CAPS-ad), um serviço que busca promover a reabilitação psicossocial, com o cuidado e atenção diária aos usuários e seus familiares, com um trabalho dentro da perspectiva de Redução de Danos (RD). Esta estratégia de tratamento é um conjunto de políticas e práticas cujo objetivo é reduzir os danos associados ao uso de drogas psicoativas em pessoas que não conseguem ou não querem parar de usá-las, ou seja, não busca a abstinência total e imediata no uso de qualquer substância psicoativa. $O$ modelo de tratamento centrado no Hospital Psiquiátrico é substituído por uma rede de atenção à saúde, em respeito aos direitos dos usuários, o que ao contrário do seu isolamento, ele recebe assistência médica em liberdade, no próprio convívio familiar e comunitário.

Palavras Chave: Redução de danos; Família; CAPS ad.

\section{ABSTRACT}

The present work presents a bibliographical research whose objective is to understand the perception of the family in relation to the Harm Reduction strategy focused on the treatment of users of CAPS-ad, since it is perceptible that a critical situation is currently experienced in relation to alcohol abuse and other drugs. In view of this reality, it was noticed the need of the implantation of a substitutive health service to the hospitalization, that responded to the demand of these users. Thus, with the need for daily care, the Alcohol and Drug Psychosocial Care Centers (CAPS-ad) were created, a service that seeks to promote psychosocial rehabilitation, with daily care and attention to users and their families, with a job within from the perspective of Harm Reduction (RD). This treatment strategy is a set of policies and practices whose objective is to reduce the damages associated with the use of psychoactive drugs in people who can not or do not want to stop using them, that is, it does not seek total and immediate abstinence in the use of any

\footnotetext{
${ }^{1}$ Endereço eletrônico de contato: monieleb@yahoo.com.br

Recebido em 15/11/2017. Aprovado pelo Conselho Editorial e aceito para publicação em 04/12/2017.
}

Rev. Psicol Saúde e Debate. Jul., 2018:4(2):25-41. 
psychoactive substance. The treatment model centered in the Psychiatric Hospital is replaced by a health care network, with respect for users' rights, which, contrary to their isolation, receive free medical care in their own family and community life.

Keywords: Harm reduction; Family; CAPS ad.

\section{INTRODUÇÃO}

Os índices de consumo de substâncias psicotrópicas estão cada vez maiores nos últimos anos, como foi apontado numa pesquisa realizada no ano de 2016, pelo Instituto Brasileiro de Geografia e Estatística (IBGE), revelando um aumento significativo do acesso precoce às bebidas alcoólicas e a drogas ilícitas entre alunos do $9^{\circ}$ ano do ensino fundamental, onde, mais da metade desses jovens (55\%, ou 1,44 milhão de alunos) relatou já ter tomado ao menos uma dose de bebida alcoólica, uma proporção superior aos 50,3\% de alunos registrados em 2012 . 0 consumo de drogas no Brasil é exacerbadamente preocupante, sendo que o país representa $20 \%$ do consumo mundial de cocaína, como também é o maior mercado de crack do mundo (Pereira, 2009).

Historicamente, percebe-se que o tratamento oferecido às pessoas consideradas socialmente desviantes foi marcado pelo enclausuramento das mesmas, onde homossexuais, prostitutas, epilépticos, pessoas sem nenhum diagnóstico de doença mental eram enviados aos manicômios. Nestes locais foram espancados, violados e viviam em um estado deplorável, em condições sub-humanas. Dentre estes, estavam os alcoolistas e os usuários de outras drogas (Arbex, 2011).

Após anos de sofrimento as pessoas que se encaixavam nesses perfis foram olhadas de perto e surgiu a necessidade de repensar sobre essa forma de tratamento, dando início ao movimento da Reforma Sanitária que buscava entre outros, maior qualidade no serviço prestado a população. Partindo desse mesmo ponto de vista surge em meados dos anos 70 a Reforma Psiquiátrica Brasileira, sendo liderado por usuários, familiares, e trabalhadores da saúde mental, tal movimento visava desconstruir especificamente esse modelo hospitalar e manicomial, que separava pessoas que propositalmente não serviam para conviver em sociedade (Jorge, 2010).

Com este quadro alarmante, emergiu a importância de se buscar soluções mais efetivas de abordagens tanto preventivas como de tratamento aos pacientes portadores de dependência de álcool e outras drogas, onde o modelo de tratamento centrado no Hospital Psiquiátrico deveria então ser substituído por uma Rede de Atenção à Saúde, em respeito aos direitos do usuário, que ao contrário de ser isolado, precisa receber assistência médica em liberdade, no próprio convívio familiar e comunitário (Oliveira, 2015).

Rev. Psicol Saúde e Debate. Jul., 2018:4(2):25-41. 
Buscando resolver este impasse, fez-se necessário a implantação de um serviço de saúde substitutivo à internação, que respondesse à demanda destes usuários, como os oferecidos pelos Centros de Atenção Psicossociais Álcool e Outras Drogas (CAPS-AD), que busca promover a reabilitação de seus usuários, com o cuidado e atenção diária aos pacientes e também aos seus familiares, com um trabalho dentro da perspectiva de Redução de Danos (Souza, \& Júnior 2017).

Esta estratégia de tratamento é um conjunto de políticas e práticas cujo objetivo é reduzir os danos associados ao uso de drogas psicoativas em pessoas que não conseguem ou não querem parar de usar drogas, ou seja, não busca a abstinência total e imediata do uso de qualquer substância psicoativa (Araujo, Marcon, Silva, \& Oliveira, 2012).

Porém, o imaginário social, principalmente no âmbito familiar, muitas vezes entende a internação como o único modelo de tratamento a estes usuários, com o foco na abstinência total e imediata da substância eleita pelo mesmo. A estratégia de Redução de Danos se destaca principalmente por não ter a abstinência como meta, mas sim o sujeito e a sua história de vida, sem ênfase na substância que o mesmo consome. (Passos, \& Souza, 2011).

Sendo assim, como a família dos usuários de álcool e outras drogas, podem colaborar com esse novo sistema sendo que eles não sabem quais os objetivos e como essa nova forma de tratamento funciona?

A partir deste contexto, tornou-se necessário um estudo a partir da revisão bibliográfica conceitual, a fim de analisar como a família entende a estratégia de Redução de Danos no tratamento dos usuários no CAPS-ad, pois o desenvolvimento desta pesquisa foi suscitado justamente pela necessidade de entender este desafio.

Então, as seções deste trabalho buscam, primeiramente, dizer sobre o consumo de álcool e outras drogas e posteriormente, contextualizar historicamente o surgimento da perspectiva de Redução de Danos no Brasil e no mundo.

A segunda seção abordará a História da Loucura no Brasil e o modelo de Assistência à Saúde antes da Instituição do Sistema Único de Saúde.

Posteriormente, uma breve apresentação da Luta Antimanicomial e a Reforma Psiquiátrica Brasileira, dando continuidade ao tema em questão, com a apresentação da nova política de Atenção à Saúde Mental e o modelo de Atenção Psicossocial.

Além destes processos de trabalho, busca-se também a proposta de discussão final sobre a participação dos familiares no tratamento de álcool e outras drogas e como entendem a estratégia de Redução de Danos no Centro de Atenção Psicossocial de Álcool e outras Drogas - CAPS-ad.

Rev. Psicol Saúde e Debate. Jul., 2018:4(2):25-41. 


\section{MÉTODOS}

A presente pesquisa foi efetivada por meio de uma revisão da literatura conceitual, utilizando-se livros, monografias, dissertações e teses disponibilizadas em bases de dados nas instituições de ensino superior, e artigos disponibilizados na base de dados da SCIELO e PEPSIC. Para a busca do material utilizou-se do cruzamento das palavras-chave: Psicologia, redução de danos, Familias, CAPs $A D$, publicadas em idioma nacional no período compreendido de 2001 a 2017.

A revisão conceitual será apresentada de forma integrativa, dividida em: Introdução, desenvolvimento e considerações finais.

\section{O Surgimento da Redução de Danos no Brasil e no Mundo}

Sabe-se que a redução de danos é uma política que almeja reduzir os danos sociais e à saúde, vinculados ao uso de substâncias psicoativas. Seu surgimento deu-se em 1926, na Inglaterra, com o intuito de tratar dependentes de substâncias psicoativas, como a heroína e a morfina, cuja intenção era receitá-los legalmente, para se obter a cura, brandindo o processo de abstinência e monitorando o seu uso, até que os usuários necessitassem de pequenas doses para que assim, vivessem com mais estabilidade (Simara, 2014).

Porém, houve oposição, como ainda há nos dias atuais, pois achavam que para uma maior eficácia recomendava-se que o uso fosse cessado abruptamente. No entanto, mesmo gerando contestações, essa forma de encarar a dependência de drogas, foi apontada como algo inovador e que anos mais tarde seria necessária ser retomada. Infelizmente, de início, com a expansão da propagação do vírus da AIDS e, posteriormente, também por causa da hepatite B, houve a necessidade de se tomar outras medidas e, assim em meados da década de 80 , na Holanda, iniciou-se o programa de troca de seringas. Neste meio tempo, a Inglaterra se organizava com estratégias de redução de danos, que além da troca de seringas incluía oportunidades de empregos e moradia, prescrição de drogas, internações, entre outras. E com o aparecimento de tantos casos das patologias já citadas, muitos países perceberam a importância de realmente buscar medidas para reduzir os danos (Fonseca, 2012).

No Brasil, apenas no final da década de 80, mais precisamente na cidade de Santos, cujo o índice de casos de AIDS era o mais alto do país, iniciou-se a troca de seringas como forma de prevenção, não perdurando por muito tempo, pois a consideraram como um encorajamento para o aumento do abuso de drogas, esta iniciativa levou a fornecer apenas hipoclorito de sódio para assepsia das seringas reutilizadas. Somente nos anos 90 a redução de danos seria sancionada em Salvador, o que acarretou problemas em relação ao controle da epidemia, baseando-se nas

Rev. Psicol Saúde e Debate. Jul., 2018:4(2):25-41. 
Conferências Anuais, o programa de redução de danos, ainda no decorrer da década de 90, ganhou força com o surgimento da Associação Brasileira de Redutores de Danos (ABORDA) e a Rede Brasileira de Redução de Danos (REDUC), quando leis foram homologadas visando a redução de danos, para diminuir as consequências da epidemia de HIV e outras patologias (Vier, \& Boarini, 2013).

Com a necessidade de atendimentos diários, em decorrência da reforma psiquiátrica nos anos 70, foram criados os Centros de Atenção Psicossociais Álcool e Drogas (CAPS-AD), um serviço que busca promover a reabilitação psicossocial de seus usuários, com o cuidado e atenção diária ao paciente e seus familiares, voltado para a perspectiva de Redução de Danos $(\mathrm{RD})$, priorizando ações sociais que reduzam marcas deixadas, visando o bem-estar. Por volta do ano de 2002, a Redução de Danos passou a ser declarada como uma das estratégias de prevenção ao uso e abuso de drogas, integrando-a ao Sistema Único de Saúde - SUS, através de serviços específicos, como os CAPS-AD. Já no ano seguinte, mais de 150 programas de Redução de Danos estavam em funcionamento no País (Tisott, Hildebrandt, Leite, Martins, \& Cosentino, 2015).

Infelizmente, a maior parte das ações se desenvolvia com pouca agregação formal com outras instâncias, sendo ainda uma situação que perdura nos dias atuais e, consequentemente a partir de 2004, muitos colaboradores tiveram suas intervenções suspensas e algumas acabaram pela falta de financiamento, no entanto, desde o ano de 2004 até os dias atuais houve uma mudança: a AIDS deixa de ser o cerne da redução de danos e o crack assume este lugar, sendo englobado à Saúde Mental (Paiva, Pupo, \& Barboza, 2006).

Assim, a Redução de Danos passa a ser apresentada como uma estratégia da Política de Atenção Integral a Usuários de Álcool e outras Drogas, divulgada pelo Ministério da Saúde, não somente com o objetivo exclusivo dos Programas de Redução de Danos e as ações de trocas de seringas, mas também com a intenção de se estabelecer ações que viabilizam os serviços da rede de apoio do SUS. Nestes, estão inclusos os serviços de saúde mental, tais como os CAPS e os serviços de atenção primária à saúde, como a Estratégia Saúde da Família - ESF (Matos, 2011).

Alguns anos mais tarde, mais precisamente em 2006, a promoção e execução da Política Nacional de Promoção da Saúde fortaleceu as ações de atenção ao usuário de drogas, preconizando a expansão de atividades preventivas e de redução de danos que incluíam o empenho e a autonomia da população, enquanto uma prática ética. Portanto, este trabalho progrediu até aprimorar seu campo de atuação para outras drogas, passando a idealizar estratégias de RD como uma política de saúde e, consequentemente progressos também foram

Rev. Psicol Saúde e Debate. Jul., 2018:4(2):25-41. 
alcançados na área dos direitos, com muitos estados e municípios elaborando legislações próprias sobre práticas de redução de danos (Souza, Kantorski, Gonçalves, Mielke, \& Guadalupe, 2007).

\section{A História da Loucura no Brasil e o Modelo de Assistência à Saúde Antes da Instituição do Sistema Único de Saúde}

Devido à chegada da família real no Brasil em meados do século XIX, depois de anos deixando os "chamados loucos" esquecidos e sem suporte, foi que se atentou para a loucura no país, sendo que a maneira encontrada para tirar os 'alienados' das ruas, principalmente os desfavorecidos socialmente e que apresentavam comportamentos agressivos, era colocando-os nos porões das Santas Casas de Misericórdia, vivendo em condições precárias (Fonte, 2012).

Alguns anos mais tarde, mais especificamente em 1852 no Rio de Janeiro, criou-se o primeiro hospital psiquiátrico, o Hospício Dom Pedro II, onde o isolamento era a prioridade. Principalmente em relação às famílias de pacientes menos favorecidos, pois aqueles com uma melhor condição financeira tinham a opção de cuidar de seu ente alienado em sua própria residência, mesmo que com dificuldades. Entre 1840 a 1889, no período conhecido como Segundo Reinado, foram fundadas mais algumas instituições em outros estados brasileiros, especificamente para os loucos (Gonçalves, \& de Sena, 2001).

A fundação destas Instituições não traria resultados tão eficazes condizentes com a demanda a ser cumprida, pois além da pouca quantidade de médicos, eles não influenciavam nas decisões a serem tomadas e desconheciam os critérios específicos para as internações, sendo que estas eram realizadas pelas autoridades públicas. Foi somente a partir do século XX que os médicos começaram a ter autonomia nestas (Resende, 2000).

Segundo Engel (2001, p. 331), mesmo sendo um meio limitado e confuso de amparo aos alienados, procurava-se legalizar a retirada das ruas daqueles considerados perigosos, com 0 intuito de proporcionar aumento de suas capacidades como pessoa.

No entanto, houve grande incoerência no objetivo, pois o que seria um meio de amparo aos loucos, na prática ocorreu diferente. Todos os tipos de Instituições que abrigavam alienados sejam elas asilos, hospitais psiquiátricos, hospícios ou quarteis policiais, tinham como função retirá-los das ruas, promovendo assim o afastamento dos loucos dos civis, que eram consideradas pessoas normais. Ficavam reclusos, aguardando apenas o dia de sua morte (Tenório, 2002).

Após a Proclamação da República houve a mudança de psiquiatria empírica para a psiquiatria científica, pois a direção dos hospitais psiquiátricos passou ao controle médico. Assim, a partir deste momento os hospícios e colônias se multiplicaram exacerbadamente, mantendo a Rev. Psicol Saúde e Debate. Jul., 2018:4(2):25-41. 
função de segregar os loucos e, ainda, por terem se deparado com um ambiente político e ideológico conveniente para o seu crescimento, considerado como um momento de progresso. Foi o momento definido como a Primeira Reforma Psiquiátrica no Brasil, é válido ressaltar que na tentativa de reconduzir cidadãos restabelecidos e capacitados à sociedade, o trabalho era utilizado como forma de tratamento (Silveira, \& Braga, 2005).

Por volta de 1923 criou-se a Liga Brasileira de Higiene Mental (LBHM), propondo aperfeiçoamentos sanitários e alteração dos hábitos e modos de vida dos indivíduos para precaver doenças mentais, pois mesmo sendo originárias por questões próprias, alguns fatores eram considerados desencadeadores, como o alcoolismo e a sífilis e em meados da década de 40, foi desenvolvido o Serviço Nacional de Doenças Mentais (SNDM), aliado ao Ministério da Educação e Saúde, sendo os hospitais públicos responsáveis por mais de $80 \%$ dos hospitais psiquiátricos brasileiros, entre eles os principais eram Juqueri (São Paulo), o Hospital de Alienados (Rio de Janeiro) e o de São Pedro (Porto Alegre) (Vechi, 2004).

Entre as décadas de 40 e 50 houve aumento de hospitais públicos e através do SNDM eram efetuados convênios para implantação de hospitais psiquiátricos. A situação dos hospitais públicos continuava desordenada, com excesso de pacientes internados, prosseguindo os hospitais psiquiátricos a terem basicamente a função social de exclusão. Naquela época a psiquiatria buscava se instituir como especialidade médica, como, por exemplo, a insulinoterapia (tratamento do diabetes mellitus através da administração exógena de insulina), a eletroconvulsoterapia (técnica que consiste na passagem de uma corrente elétrica de alta voltagem sobre a região temporal), a fim de provocar dessincronização traumática da atividade cerebral do paciente com perda da consciência, usada como terapia em casos de problemas mentais graves, também chamado de eletrochoque (Botti, 2007).

Em outros países, como França, Inglaterra e Estados Unidos, o tratamento asilar foi se remodelando e até mesmo alterado, preconizando rearranjos técnico-científicos e administrativos da psiquiatria. No Brasil partir da década de 1960, constata-se uma acentuada amplificação da rede de hospitais psiquiátricos (Nunes, Jucá, \& Valentim, 2007).

Após o golpe militar em 1964, uma nova fase se iniciava no Brasil, sendo que os governos militares fortificaram a internação asilar e a privatização da assistência, negociando leitos com clínicas e hospitais psiquiátricos conveniados, custeados pelo Sistema Único de Saúde (SUS). Esta fase foi chamada de "Indústria da Loucura" devido às demasiadas internações, que muitas vezes, além de desnecessárias, eram prolongadas pelas clínicas e hospitais psiquiátricos particulares, visando o lucro. Sendo assim em 1970 deu-se início à discussão a respeito da necessidade de humanização do tratamento ao doente mental, impulsionando diferentes âmbitos

Rev. Psicol Saúde e Debate. Jul., 2018:4(2):25-41. 
brasileiros. A Associação Brasileira de Psiquiatria (ABP) argumentava em favor de médicos que haviam sido presos e torturados e estimulavam discussões éticas em torno dos direitos humanos e da necessidade de expansão dos direitos individuais no país (Hirdes, 2009).

Foi solicitado para que ninguém fosse sujeitado à tortura ou castigo cruel, e nem preso, detido ou exilado, sendo estendidos para a situação de opressão do doente mental nos manicômios e sua humilhação moral na sociedade. Os hospitais psiquiátricos, que na realidade eram exclusivos na oferta de serviços psiquiátricos no cenário nacional, tiveram a situação de maus tratos, violência e tortura aos internos desnudadas e denunciadas na sociedade brasileira, o que rendeu descontentamento, originando debates para a sustentação do Movimento Antimanicomial. Todavia, ainda não se tinha uma clara consciência de qual estratégia de cuidado e nem uma proposta estruturada para a intervenção clínica (Yasui, 2010).

No ano de 1978, após o surgimento de denúncias de agressões, estupros, trabalhos escravos e mortes não esclarecidas, houve confluência por parte dos trabalhadores da saúde mental, com o objetivo de batalhar por transformações no sistema. Partindo deste contexto, deuse início a congressos e encontros relevantes em várias partes do Brasil, marcando assim, o primórido à trajetória da Reforma Psiquiátrica Brasileira, fazendo-se necessário aprofundarmos mais neste cenário, buscando conhecer o marco que rompeu com a segregação social dos loucos (de Barros, 2003).

\section{A Luta Antimanicomial e a Reforma Psiquiátrica Brasileira}

Decorrente da Declaração de Caracas de 1990, que foi aceita com êxito pela Conferência Regional para a Reestruturação da Assistência Psiquiátrica dentro do Sistema Local de Saúde, originou-se assim, uma legislação em Saúde Mental denominada de Reforma Psiquiátrica Brasileira. Em função de o Brasil ter engajado-se a esta declaração, juntamente com uma alvoroçada movimentação por parte de funcionários da Saúde Mental, criou-se a Lei n. 9.867, de 10 de novembro de 1999, a qual aprova a ampliação de projetos para auxílio psicossocial para pacientes psiquiátricos assistidos por serviços comunitários (Berlinck, Magtaz, \& Teixeira, 2008).

Em 6 de abril de 2001, o Governo Federal decreta a Lei n. 10.216 que determina sobre o resguardo e os benefícios das pessoas com transtornos mentais e redireciona o modelo Assistencial em Saúde Mental. Teve como sustentação o projeto original do deputado Paulo Delgado e engloba propostas pertinentes ao projeto original. A lei redireciona o paradigma da assistência psiquiátrica, rege a cautela com a clientela internada por tempos prolongados e supõe a viabilidade de penalidade para a internação voluntária desnecessária ou opressora. Independentemente dos múltiplos aperfeiçoamentos a nível nacional, a reforma psiquiátrica,

Rev. Psicol Saúde e Debate. Jul., 2018:4(2):25-41. 
ainda retrata muitos empecilhos na gestão de uma rede de Atenção em Saúde Mental, como a forma de aplicação de recursos financeiros do SUS, pois apesar do decrescimento significativo, mas insatisfatório, ainda existem gastos com internação psiquiátrica, ou seja, prevalecente ainda o modelo hospitalar (Goulart, \& Durães,2010).

\section{Nova Política de Atenção à Saúde Mental e o Modelo de Atenção Psicossocial}

Os princípios e diretrizes do Sistema Único de Saúde (SUS) são balizadores para a Política de Saúde Mental, que segue e respeita os ideais da Reforma Psiquiátrica Brasileira de inclusão social e desestigmatização. Reduzir progressivamente a internação psiquiátrica hospitalar é o redirecionamento principal do Ministério da Saúde (MS), ao modelo assistencial em Saúde Mental. Em decorrência da reforma psiquiátrica nos anos 70, fez-se necessário a implantação de um serviço de saúde substitutivo à internação, que respondesse às demandas destes usuários com atendimento multiprofissional. Estes serviços teriam papel estratégico como substitutivos ao hospital psiquiátrico no tratamento de pessoas acometidas por transtornos mentais, e dentre elas, as portadoras de dependência de álcool e outras drogas (Romanini, \& Roso, 2012).

A partir da portaria 336/MG, criou-se os CAPS-AD, que busca promover a reabilitação psicossocial de seus usuários, cuidado e atenção diária não só ao paciente, como também aos seus familiares, com um trabalho voltado para a perspectiva da Estratégia de Redução de Danos (RD), priorizando meios de inserção social, visando o bem-estar (Bezarra Jr, 2007).

Esta estratégia de tratamento é um conjunto de políticas e práticas com o objetivo de reduzir os danos associados ao uso de drogas psicoativas em pessoas que não conseguem ou não querem parar de usar drogas, ou seja, não prioriza a abstinência total e imediata no uso de qualquer substância psicoativa (Machado \& Boarini, 2013).

Diante do sofrimento causado pelo usuário, muitas vezes o familiar entende como forma de tratamento, apenas o modelo asilar de isolamento social, desconhecendo a lógica de tratamento pautada no usuário como protagonista do mesmo, implantada no CAPS-ad. Este modelo de tratamento está centrado numa rede de atenção à saúde, que respeita os direitos do usuário, que em vez de ser isolado, recebe assistência à saúde em liberdade, no próprio convívio familiar e comunitário, por serem estes serviços ainda em formação, percebe-se que são também revestidos de expectativas, principalmente na perspectiva do familiar, como uma ponte para atingir o objetivo da abstinência, contrariando assim, a proposta de tratamento pautada na estratégia de Redução de Danos (Garcia, Leal, \& Abreu, 2008).

Rev. Psicol Saúde e Debate. Jul., 2018:4(2):25-41. 
Sendo assim, sabe-se que os usuários necessitam de ajuda, por isso prioriza-se o desenvolvimento de ações que os auxiliem, mas em contrapartida, é necessário refletir que além de se adotar medidas para tratar os danos causados pelo álcool e outras drogas aos usuários, deve-se também atentar para o sofrimento de seus familiares, que a cada dia renovam a esperança de cura de seus entes queridos.

\section{A Visão da Família em Relação ao Tratamento}

$\mathrm{Na}$ literatura existem diversos significados para a palavra 'família', podendo-se destacar que é "um grupo de indivíduos que se encontram ligados por hábitos, costumes, comportamentos ou interesses oriundos de um mesmo local; que possuem qualidades ou particularidades semelhantes". De um modo geral, as famílias são vistas como parte essencial na vida das pessoas, pode-se dizer que são a base, um alicerce que contribui no crescimento de cada indivíduo, tanto físico e mental, como socialmente (Oliveira, Bittencourt, \& Carmo, 2008).

O universo familiar é de extrema importância na vida de qualquer indivíduo e interfere diretamente em suas condutas futuras. Os fatores relacionados aos vícios podem ser oriundos da família, pois desde a infância os jovens podem encontrar afeto, moralidade, limites e atenção, entre outros fatores, em seu meio familiar. Mas podem também encontrar a falta destes valores, o que pode acarretar consequências negativas graves, como por exemplo, a prostituição, roubos e o abuso de álcool e outras drogas. O contexto familiar de jovens envolvidos pelo álcool e outras drogas é apontado como problemático, até mesmo o uso excessivo de psicotrópicos pode estar relacionado à cultura familiar, sendo que os jovens, ao decorrer dos anos presenciam o uso, às vezes abusivo, de medicamentos por parte daqueles que fazem parte do seu convívio familiar (Guimarães, Hochgraf, Brasiliano, \& Ingberman, 2009).

A formação de um indivíduo é dividida em fases, podendo-se ressaltar que a adolescência é uma delas, considerada como um ponto de transição de suma importância, onde ocorre o desenvolvimento humano, caracterizada pela passagem à juventude, com início após a puberdade. Mediante esses fatos, alguns autores classificam que o adolescente, devido a fatores extrínsecos, está mais suscetível a experimentar o álcool ou outras drogas, uma vez que esta fase vivenciada caracteriza-se pela procura de novas sensações e descobertas Alvarez, Gomes, Oliveira, \& Xavier,(2012).

Em relação aos fatores extrínsecos, podem ser citados tanto o círculo de amizades como um dos causadores do uso de substâncias ilícitas, inicialmente influenciado por algum indivíduo já adicto. Mas as festas, principalmente as 'Festas Rave', também são um dos coeficientes que influenciam no uso de álcool e outras drogas, sendo um meio onde estas são utilizadas

Rev. Psicol Saúde e Debate. Jul., 2018:4(2):25-41. 
espontaneamente e em descomedimento, no entanto, o uso de drogas pode interessar também com outros objetivos, como a diversão, denotado como algo para socialização e descontração, sem aparentes problemas evidenciados e, o uso experimental pode ser descrito como os primeiros episódios de uso, sendo estes breves e nem sempre repetitivos (Schenker, \& Souza Minayo, 2005).

Percebe-se que a maioria dos familiares entendem a dependência não como doença, pois associam a sua origem a fundamentos extrínsecos como frustração profissional ou decepção amorosa. Devido a fase de a adolescência merecer muita atenção por ser um período considerado mais suscetível ao uso de álcool e outras drogas, é preciso explanar ao adolescente acerca da cautela devida em relação às companhias, festas e ao uso de álcool e outras drogas. É conveniente vislumbrar o desejo e o prejuízo mediante o envolvimento grupal, as atribuições tanto da escola como da família, e ainda a mídia, não podendo ser considerados fatores sem influência (Silva, Oliveira, \& Costa, 2007).

Assim, tratando-se do uso abusivo de álcool e outras drogas, a família é o ponto de apoio que o dependente químico necessita no decorrer do período de tratamento. É importante ressaltar a inclusão das famílias no CAPS-ad, pois são a base de onde origina os valores adquiridos, os quais futuramente formarão um cidadão. É através destas que se inicia o enfrentamento dos problemas acarretados pelo o uso do álcool e outras drogas, mas as quais diante dos obstáculos, também ficam adoecidas e necessitam de suporte (Tavares, Béria, \& de Lima, 2004).

Diante da realidade de que a perspectiva brasileira em relação à dependência química é voltada para a cura, considerada apenas quando há a abstinência total do uso de álcool e/ou drogas, faz-se necessário prestar informações aos familiares acerca do tratamento oferecido pelos CAPS, sendo importante enfatizar a importância do apoio destes prestado ao usuário .Um ponto crucial é o imediatismo do familiar, o qual se direciona à solução eficaz, com a demanda inicial de internação como meio de cura, sendo esta muitas vezes involuntárias ou compulsórias, ou seja, sem a aceitação e o consentimento do usuário, uma vez que a urgência geralmente é da família (Rebolledo, de Medina, \& Pillon, 2004).

Para muitas destas, a internação solucionaria todos os empecilhos, no entanto, a cooperação familiar é primordial, pois o processo terapêutico necessita desta integração. Em relação a um estudo realizado em Sobral - CE, 45,3\% das famílias atendidas no CAPS-AD da cidade, desacreditavam na possibilidade de resultados otimistas e nem mesmo depositavam confiança no êxito de seus entes queridos em relação ao tratamento. Algo relevante seria

Rev. Psicol Saúde e Debate. Jul., 2018:4(2):25-41. 
elucidar que a recaída é um ponto que faz parte do tratamento, para que assim a aflição vinculada ao processo seja, pelo menos, minimizada (Borini, Guimarães, \& Borini, 2003).

Sabe-se que a atuação dos Centros de Atenção Psicossocial para Álcool e outras Drogas no Brasil ocorre há pouco tempo e a repercussão dos trabalhos já realizados ainda não foram adequadamente apreciados. Os profissionais que trabalham nesta área não foram acertadamente instruídos ao decorrer de sua jornada universitária, a orientar e debater sobre as mais variadas particularidades associadas à dependência química (Borba, \& Cunha, 2016).

Compreender e expor a mesma como um estado permanente, uma repetição de quedas e avanços, necessita-se de uma boa diretriz à família. No entanto, o ponto de vista sobre o adoecimento biológico pode ocasionar também um afastamento do familiar mediante aos obstáculos da dependência química (Gonçalves, S. S. P. M., \& Tavares, 2007).

Quando a abstinência inicial é alcançada depois de um período de tratamento, aparentemente indica algo determinado, ou seja, a cura, muitas vezes a família entende este fato como uma cura que foi alcançada, acreditando que todos os impasses foram solucionados abruptamente em poucos dias, devido ao afastamento do uso. Mas nem sempre este quadro se mantém. Por isto é tão importante que as famílias e usuários identifiquem que as recaídas são imprescindíveis neste processo, sendo primordial que a equipe de profissionais envoltos no tratamento elucide sobre essas questões. É significativo conceituar que o tratamento da dependência química não se limita apenas naquele que é declarado como adicto, portanto, abordar psicossocialmente aqueles de seu convívio, como a família, é muito importante (Coelho, Scisleski, \& Maraschin, 2008).

O CAPS-AD possibilita ao sujeito conhecer a sua realidade em relação ao uso e/ou abuso de álcool e outras drogas, os pontos onde ocorrem as suas dificuldades, sendo este o objetivo da redução de danos: buscar a promoção da responsabilidade do usuário em se cuidar, mesmo que continue a fazer uso destas substâncias. Se o sujeito é internado pela família, pode acontecer dele não se implicar nesta realidade, pois a partir do momento que ele está "preso", pode impedi-lo de perceber as dificuldades acarretadas pelo seu uso abusivo de álcool e outras drogas (Freire, Santos, Bortolini, Moraes, \& Oliveira, 2012).

Quando uma pessoa que usa drogas chega a um serviço de saúde dizendo que não quer ou não consegue parar de usar drogas, ela testa nossos compromissos, pois se o tratamento é para todos, então inclui também quem não quer parar de usá-las. Para se pensar o ser humano por inteiro então deve-se olhar para além do uso de drogas, acolhendo outras demandas, sem condicionar o cuidado voltado apenas para a abstinência. Ao perceber o sujeito em suas

Rev. Psicol Saúde e Debate. Jul., 2018:4(2):25-41. 
singularidades sem diminuí-lo, é preciso pensar projetos terapêuticos igualmente singulares (Vieira, Carvalho, Azevedo, Silva, \& Ferreira, 2010).

É necessário refletir sobre a noção de "abstinência". Algo muito mais condizente à ética de militantes da Luta Antimanicomial é a ideia de um projeto terapêutico radicalmente singular, em que a abstinência pode eventualmente ser alcançada em um processo, porém jamais ser colocada como objetivo pré-determinado no início da caminhada (Fraga, \& Silva, 2010).

\section{CONSIDERAÇÕES FINAIS}

O uso abusivo de drogas não é recente, sempre foram usadas socialmente de modo natural, até se tornarem uma questão de saúde pública, isso tem sido visto na atualidade como um problema de saúde pública, diferentemente de períodos passados, onde não se priorizou buscar as devidas providências em relação à prevenção e tratamento de transtornos decorrentes do consumo de álcool e outras drogas

Mesmo diante da complexidade do problema, o Estado se absteve, e as possibilidades de tratamentos específicos para usuários de álcool e outras drogas, eram sustentadas apenas pelas práticas médicas, geralmente psiquiátricas, visando principalmente alcançar a abstinência, cujos tratamentos eram voltados ao regime de exclusão e separação do usuário de drogas do seu convívio social.

Para suprir a demanda atual, faz-se necessário um comprometimento composto por diversos setores tanto da sociedade quanto de instituições como a escola, campos da saúde e da segurança, além do foco transmitido sobre as drogas pelos meios de comunicação, as redes de saúde, mais especificamente os CAPS, devem incumbir-se na estruturação de apoio em saúde mental executando tanto seus papeis no auxílio e na organização dos serviços de saúde, quanto na promoção da vida e da autonomia dos usuários, vinculando os mecanismos já existentes em outras redes, como os meios culturais, sociais, afetivos, econômicos, religiosos e de lazer.

Portanto, em consequência da provável insuficiência de compreensão sobre a redução de danos, tanto no meio acadêmico como na prática, a solução dos obstáculos entre segurança e saúde estabilizou-se somente na teoria, embora de modo parcial, sendo que na prática estes dois pontos chaves se mantém ainda de maneira incerta.

Este fato se dá devido ao longo dos tempos, o tratamento ter sido atrelado à ideia central da internação hospitalar, não havendo outras propostas de atenção à saúde em rede de serviços que direcionasse o cuidado para uma atenção longitudinal e contínua.

Rev. Psicol Saúde e Debate. Jul., 2018:4(2):25-41. 
Além disso, a internação na maioria das vezes é realizada de uma forma inesperada e muitas vezes precipitada, sob a contrariedade do sujeito, onde se busca utilizar estratégias como forma de sucumbir a pessoa a este tipo de tratamento imposto. Este saber científico herdado do modelo asilar de isolar, observar, classificar e determinar o usuário de drogas refletiu no afastamento da família no processo de assistência, o que pode proporcionar a redução dos vínculos com os mesmos, bem como do apoio e circulação destes usuários nos espaços sociais.

Pode-se afirmar que o imaginário social ainda é perpassado pela influência deste modo de atenção à saúde, sendo necessário prestar informações sobre a proposta dos CAPS, como serviços substitutos dos manicômios, onde as ações de saúde priorizam o sujeito como peça central na determinação do seu próprio cuidado. É preciso buscar junto ao usuário a consideração pelo valor da sua vida e, conjuntamente, romper com os rótulos e estigmas acerca da doença mental e da adição das drogas.

Assim, é possível concluir que ainda há uma extensa trajetória a ser atravessada, embora alguns passos já foram alcançados através da idealização da atual política e dos recentes serviços em saúde mental.

\section{REFERÊNCIAS}

Alvarez, S. Q., Gomes, G. C., Oliveira, A. M. N., \& Xavier, D. M. (2012). Grupo de apoio/suporte como estratégia de cuidado: importância para familiares de usuários de drogas. Revista Gaúcha de Enfermagem, 33(2), 102-108.

Araujo, N. B. D., Marcon, S. R., Silva, N. G., \& Oliveira, J. R. T. D. (2012). Perfil clínico e sociodemográfico de adolescentes que permaneceram e não permaneceram no tratamento em um CAPSad de Cuiabá/MT. Jornal Brasileiro de Psiquiatria, 61(4), 227-234.

Arbex, D. (2011). Holocausto brasileiro: 50 anos sem punição. Tribuna de Minas, 20.

Berlinck, M. T., Magtaz, A. C., \& Teixeira, M. (2008). A reforma psiquiátrica brasileira: perspectivas e problemas. Revista Latinoamericana de Psicopatologia Fundamental, 11(1), 21-27.

Bezarra Jr, B. (2007). Desafios da reforma psiquiátrica no Brasil. Physis: Revista de Saúde Coletiva, 17(2), 243-250

Borba, S., \& Cunha, V. (2016). Atuação da psicologia contra o suicídio nos centros de atenção de atenção psicossocial. Psicologia e Saúde em debate, 2(Supl. 1), 35-38.

Rev. Psicol Saúde e Debate. Jul., 2018:4(2):25-41. 
Borini, P., Guimarães, R. C., \& Borini, S. B. (2003). Usuários de drogas ilícitas internados em hospital psiquiátrico: padrões de uso e aspectos demográficos e epidemiológicos. J Bras Psiquiatr, 52(3), 171-9.

Botti, N. C. L. (2007). Uma viagem na história da enfermagem psiquiátrica no início do século XX. Esc Anna Nery R Enferm, 10(4), 725-729.

Coelho Scisleski, A. C., \& Maraschin, C. (2008). Internação psiquiátrica e ordem judicial: saberes e poderes sobre adolescentes usuários de drogas ilícitas. Psicologia em Estudo, 13(3).

de Barros, R. B. (2003). Reforma Psiquiátrica Brasileira: resistências e capturas em tempos neoliberais. Loucura, ética e política: escritos militantes.

Engel, M. G. (2001). Os delírios da razão: médicos, loucos e hospícios (Rio de Janeiro, 18301930). Fiocruz 20.

Fonseca, C. J. B. (2012). Conhecendo a redução de danos enquanto uma proposta ética. Psicologia \& Saberes, 1(1), 11-36.

Fonte, E. M. M. (2012). Da institucionalização da loucura à reforma psiquiátrica: as sete vidas da agenda pública em saúde mental no Brasil. Estudos de Sociologia, 1(18), 1-24.

Fraga, D., \& Silva, J. (2010). Os Grupos de Apoio e Reflexão com as Familias e os Dependentes Quimicos (álcool e outras drogas). Anais do Salão Internacional de Ensino, Pesquisa e Extensão, 2(1).

Freire, S. D., Santos, P. L. D., Bortolini, M., Moraes, J. F. D. D., \& Oliveira, M. D. S. (2012). Intensidade de uso de crack de acordo com a classe econômica de usuários internados na cidade de Porto Alegre/Brasil.

Garcia, M. L. T., Leal, F. X., \& Abreu, C. C. (2008). A política antidrogas brasileira: velhos dilemas. Revista Psicologia \& Sociedade, 20(2).

Gonçalves, A. M., \& de Sena, R. R. (2001). A reforma psiquiátrica no Brasil: contextualização e reflexos sobre o cuidado com o doente mental na família. Revista latino-americana de Enfermagem, 9(2), 48-55.

Gonçalves, S. S. P. M., \& Tavares, C. M. D. M. (2007). Atuação do enfermeiro na atenção ao usuário de álcool e outras drogas nos serviços extra-hospitalares. Esc anna nery rev enferm, 11(4), 586-92.

Goulart, M. S. B., \& Durães, F. (2010). A reforma e os hospitais psiquiátricos: histórias da desinstitucionalização. Revista Psicologia \& Sociedade, 22(1).

Hirdes, A. (2009). A reforma psiquiátrica no Brasil: uma (re) visão. Ciência \& Saúde Coletiva, 14(1).

Jorge, A. C. R. (2010). Analisando o perfil dos usuários de um CAPS AD. URFGS: Repositório Digital.

Machado, L. V., \& Boarini, M. L. (2013). Políticas sobre drogas no Brasil: a estratégia de redução de danos. Psicologia Ciência e Profissão, 33(3), 580-595.

Rev. Psicol Saúde e Debate. Jul., 2018:4(2):25-41. 
Matos de Andrade, T. (2011). Reflexões sobre políticas de drogas no Brasil. Ciência \& Saúde Coletiva, 16(12).

Nunes, M., Jucá, V. J. D. S., \& Valentim, C. P. B. (2007). Ações de saúde mental no Programa Saúde da Família: confl uências e dissonâncias das práticas com os princípios das reformas psiquiátrica e sanitária.

Oliveira, E. B. D., Bittencourt, L. P., \& Carmo, A. C. D. (2008). A importância da família na prevenção do uso de drogas entre crianças e adolescentes: papel materno. SMAD. Revista eletrônica saúde mental álcool e drogas, 4(2).

Oliveira, J. A. P. (2015). "Eu bebo sim": percurso de alcoolistas em um Centro de Atenção Psicossocial - CAPS-ad. Dissertação de Mestrado em Psicologia, Universidade de Franca, Franca, SP.

Paiva, V., Pupo, L. R., \& Barboza, R. (2006). O direito à prevenção e os desafios da redução da vulnerabilidade ao HIV no Brasil. Revista de saúde pública, 40, 109-119

Passos, E. H., \& Paula Souza, T. (2011). Redução de danos e saúde pública: construções alternativas à política global de "guerra às drogas". Psicologia \& Sociedade, 23(1).

Pereira, M. O. (2009). Análise da política do Ministério da Saúde do Brasil para a atenção integral dos usuários de álcool e outras drogas (Doctoral dissertation, Universidade de São Paulo).

Rebolledo, E. A. O., de Medina, N. M. O., \& Pillon, S. C. (2004). Fatores de riscos associados ao uso de drogas entre estudantes adolescentes. Revista Latino-Americana de Enfermagem, 12(spe), 369-375.

Resende, H. (2000). Política de saúde mental no Brasil: uma visão histórica. In Cidadania e loucura: políticas de saúde mental no Brasil (pp. 15-73).

Romanini, M., \& Roso, A. (2012). Mídia e crack: promovendo saúde ou reforçando relações de dominação?. Psicologia Ciência e Profissão, 32(1).

Sampaio, F. F. F., Duarte, S. R., Rocha, N. N. V., Rocha, S. P., Morais, T. T. M., \& Alves, R. D. (2015). Grupo de familiares em CAPS AD: acolhendo e reduzindo tensões. Sanare - Revista de Políticas Públicas, 14(1), 81-86.

Schenker, M., \& de Souza Minayo, M. C. (2005). Fatores de risco e de proteção para o uso de drogas na adolescência. Ciência \& Saúde Coletiva, 10(3).

Silva, C. A. F., Oliveira, E. N., \& Costa, M. A. S. (2007). Concepções dos familiares de dependentes químicos atendidos no Centro de Atenção Psicossocial para álcool e outras drogas (CAPS-AD) de Sobral - CE. Sanare - Revista de Políticas Públicas, 6(2), 67-76.

Silveira, L. C., \& Braga, V. A. B. (2005). Acerca do conceito de loucura e seus reflexos na assistência de saúde mental. Revista Latino-Americana de Enfermagem, 13(4), 591-595

Simara Novaes, P. (2014). O tratamento da dependência química e o ordenamento jurídico brasileiro. Revista Latinoamericana de Psicopatologia Fundamental, 17(2).

Rev. Psicol Saúde e Debate. Jul., 2018:4(2):25-41. 
Souza, J. D., Kantorski, L. P., Gonçalves, S. E., Mielke, F. B., \& Guadalupe, D. B. (2007). Centro de Atenção Psicossocial Álcool e Drogas e Redução de Danos: novas propostas, novos desafios. Rev. enferm. UERJ, 15(2), 210-217.

Souza, M. C., \& Júnior, G. A. (2017). O Perfil do Atendido e dos profissionais que compõem o tratamento das drogas em comunidades terapêuticas. Psicologia e Saúde em debate, 2(2), 112-123.

Tavares, B. F., Béria, J. U., \& de Lima, M. S. (2004). Fatores associados ao uso de drogas entre adolescentes escolares. Revista de Saúde Pública, 38(6), 787-796.

Tenório, F. (2002). A reforma psiquiátrica brasileira, da década de 1980 aos dias atuais: história e. História, Ciências, Saúde. Manguinhos, 9(1), 25-59.

Tisott, Z. L., Hildebrandt, L. M., Leite, M. T., Martins, R. V., \& Cosentino, S. F. (2015). Álcool e outras drogas e a implantação da política de redução de danos no Brasil: Revisão narrativa. Revista de Atenção à Saúde (antiga Rev. Bras. Ciên. Saúde), 13(43).

Vechi, L. G. (2004). latrogenia e exclusão social: a loucura como objeto do discurso científico no Brasil. Estudos de psicologia, 9(3), 489-495.

Vieira, J. K. S., Carvalho, R. N., Azevedo, E. B., Silva, P. M. C., \& Ferreira, M. O., Filha. (2010). Concepção sobre drogas: relatos dos usuários do CAPS-AD, de Campina Grande, PB. SMAD - Revista Eletrônica Saúde Mental Álcool e Drogas, 6(2), 274-295.

Vier Machado, L., \& Boarini, M. L. (2013). Políticas sobre drogas no Brasil: a estratégia de redução de danos. Psicologia Ciência e Profissão, 33(3).

Yasui, S. (2010). Rupturas e encontros: desafios da reforma psiquiátrica brasileira. SciELOEditora FIOCRUZ.

Rev. Psicol Saúde e Debate. Jul., 2018:4(2):25-41. 